\title{
Congenital hypogonadotropic hypogonadism and constitutional delay of growth and puberty have distinct genetic architectures
}

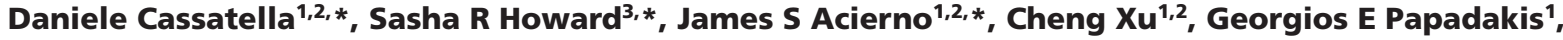 \\ Federico A Santoni ${ }^{1}$, Andrew A Dwyer ${ }^{1,2}$, Sara Santini ${ }^{1}$, Gerasimos P Sykiotis ${ }^{1}$, Caroline Chambion ${ }^{1}$, \\ Jenny Meylan', Laura Marino', Lucie Favre', Jiankang Li' ${ }^{45}$, Xuanzhu Liư ${ }^{4}$, Jianguo Zhang ${ }^{4,5}$, \\ Pierre-Marc Bouloux ${ }^{6}$, Christian De Geyter ${ }^{7}$, Anne De Paepe ${ }^{8}$, Waljit S Dhillo ${ }^{9}$, Jean-Marc Ferrara ${ }^{10}$, \\ Michael Hauschild ${ }^{1}$, Mariarosaria Lang-Muritano ${ }^{11}$, Johannes R Lemke ${ }^{12}$, Christa Flück ${ }^{13}$, Attila Nemeth ${ }^{14}$, \\ Franziska Phan-Hug', Duarte Pignatelli15, Vera Popovic ${ }^{16}$, Sandra Pekic ${ }^{16,17}$, Richard Quinton ${ }^{18}$, Gabor Szinnai ${ }^{19}$, \\ Dagmar I'Allemand ${ }^{20}$, Daniel Konrad ${ }^{11}$, Saba Sharif21, Özlem Turhan lyidir²2, Brian J Stevenson ${ }^{23}$, \\ Huanming Yang ${ }^{4,24}$, Leo Dunkel ${ }^{3, *}$ and Nelly Pitteloud ${ }^{1,2,+}$
}

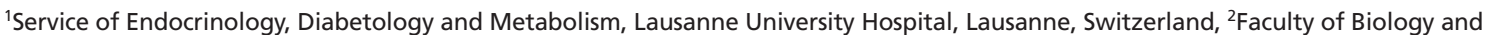
Medicine, University of Lausanne, Lausanne, Switzerland, ${ }^{3}$ Centre for Endocrinology, William Harvey Research Institute, Barts and the London School of Medicine and Dentistry, Queen Mary University of London, London, UK, ${ }^{4} \mathrm{BGI}$-Shenzhen, Shenzhen, China, ${ }^{5}$ Shenzhen Key Laboratory of Neurogenomics, BGI-Shenzhen, Shenzhen, China, ${ }^{6}$ Centre for Neuroendocrinology (Royal Free Campus), University College London, London, UK, ' University Hospital Basel, Clinic of Gynecological Endocrinology and Reproductive Medicine, Basel, Switzerland, ${ }^{8}$ Center for Medical Genetics, Ghent University Hospital, Ghent, Belgium, ${ }^{9}$ Section of Investigative Medicine, Imperial College London, Hammersmith Hospital, London, UK, ${ }^{10}$ Rue du Curtil-Maillet, Yverdon-les-Bains, Switzerland, ${ }^{11}$ Division of Pediatric Endocrinology and Diabetology and Children's Research Centre, University Children's Hospital, Zurich, Switzerland, ${ }^{12}$ Institute of Human Genetics, University of Leipzig Hospitals and Clinics, Leipzig, Germany, ${ }^{13}$ Pediatric Endocrinology and Diabetology, Department of Clinical Research, University Children's Hospital Bern, Bern, Switzerland, ${ }^{14} \mathrm{St}$. John's Hospital, Budapest, Hungary, ${ }^{15}$ Serviço de Endocrinologia, Diabetes e Metabolismo, Hospital de São João e Faculdade de Medicina do Porto, Porto, Portugal, ${ }^{16}$ School of Medicine, University of Belgrade, Belgrade, Serbia, ${ }^{17} \mathrm{Clinic}$ for Endocrinology, Diabetes and Diseases of Metabolism, University Clinical Center, Belgrade, Serbia, ${ }^{18}$ Department of Endocrinology, Institute for Human Genetics, University of Newcastle-upon-Tyne, Newcastle-upon-Tyne, UK, ${ }^{19}$ University of Basel Chidren's Hospital, Basel, Switzerland, ${ }^{20}$ Department of Endocrinology, Children's Hospital of Eastern Switzerland, St Gallen, Switzerland, ${ }^{21} \mathrm{Clinical}$ Genetics Unit, Birmingham Women's Hospital, Birmingham, UK, ${ }^{22}$ Department of Endocrinology and Metabolism, Gazi University Faculty of Medicine, Ankara, Turkey, ${ }^{23}$ SIB Swiss Institute of Bioinformatics, Lausanne, Switzerland, and ${ }^{24}$ James D. Watson Institute of Genome Sciences, Hangzhou, China

Correspondence should be addressed to $\mathrm{N}$ Pitteloud Email nelly.pitteloud@chuv.ch

\section{Abstract}

Objective: Congenital hypogonadotropic hypogonadism $(\mathrm{CHH})$ and constitutional delay of growth and puberty (CDGP) represent rare and common forms of GnRH deficiency, respectively. Both CDGP and CHH present with delayed puberty, and the distinction between these two entities during early adolescence is challenging. More than 30 genes have been implicated in $\mathrm{CHH}$, while the genetic basis of CDGP is poorly understood.

Design: We characterized and compared the genetic architectures of CHH and CDGP, to test the hypothesis of a shared genetic basis between these disorders.

Methods: Exome sequencing data were used to identify rare variants in known genes in CHH $(n=116), \operatorname{CDGP}(n=72)$ and control cohorts ( $n=36874$ ExAC and $n=405$ CoLaus).

Results: Mutations in at least one $\mathrm{CHH}$ gene were found in $51 \%$ of $\mathrm{CHH}$ probands, which is significantly higher than in CDGP $\left(7 \%, P=7.6 \times 10^{-11}\right)$ or controls $\left(18 \%, P=5.5 \times 10^{-12}\right)$. Similarly, oligogenicity (defined as mutations in more than one gene) was common in $\mathrm{CHH}$ patients $(15 \%)$ relative to $\operatorname{CDGP}(1.4 \%, P=0.002)$ and controls $\left(2 \%, P=6.4 \times 10^{-7}\right)$.

Conclusions: Our data suggest that CDGP and $\mathrm{CHH}$ have distinct genetic profiles, and this finding may facilitate the differential diagnosis in patients presenting with delayed puberty.

European Journal of Endocrinology (2018) 178, 377-388 Printed in Great Britain

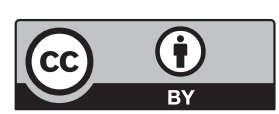

This work is licensed under a Creative Commons Attribution 4.0 International License. 


\section{Introduction}

Congenital hypogonadotropic hypogonadism (CHH (MIM: 146110)) is a rare disorder affecting approximately 1 in 4000 births (1). It is caused by GnRH deficiency, and subsequently results in altered activation of the hypothalamic-pituitary-gonadal (HPG) axis that controls sexual maturation and fertility. Clinically, $\mathrm{CHH}$ presents as absent/incomplete puberty and infertility. It is characterized by isolated low sex steroids in the setting of low (or inappropriately normal) serum gonadotropins in the absence of other hypothalamo-pituitary defects. Clinically, $\mathrm{CHH}$ is a heterogeneous disorder. In the presence of anosmia (the inability to smell) in approximately 50\% of $\mathrm{CHH}$ probands, the condition is termed Kallmann syndrome (KS (MIM: 308700)). Other associated phenotypes such as hearing loss, synkinesia, renal agenesis, ataxia and cleft lip/palate are also observed with variable frequency (2). Interestingly, a higher than expected proportion (10\%) of family members of $\mathrm{CHH}$ probands report a history of delayed puberty (3). Moreover, reversal of hypogonadotropic hypogonadism in $\mathrm{CHH}$ patients after discontinuing hormone therapy also points to a clinical overlap between the two entities (4). Therefore, congenital delay of growth and puberty (CDGP), also termed selflimited delayed puberty, and $\mathrm{CHH}$ appear to be part of the same clinical spectrum - one being classically described as transient (CDGP) and the other as permanent (CHH) (3). In contrast to $\mathrm{CHH}$, CDGP is a common disease, observed in $2-2.5 \%$ of the population (5).

Since the initial genetic report implicating KAL1 (now ANOS1) $(6,7)$, the genetics of CHH has been widely studied. Similar to its diverse clinical presentation, the genetic architecture of $\mathrm{CHH}$ is also heterogeneous, with several modes of inheritance having been described including autosomal dominant, autosomal recessive, $\mathrm{X}$-linked and de novo. Mutations in more than 30 genes have been shown to cause $\mathrm{CHH}$ (2); however, they only account for approximately 35\% of cases (8). Defects in genes involved in GnRH neuron development and olfactory system usually result in KS, whereas mutations in genes involved in GnRH secretion or homeostasis result in normosmic $\mathrm{CHH}$ (nCHH). Interestingly, clinical overlap between $\mathrm{KS}$ and $\mathrm{nCHH}$ has been reported, with a disease spectrum rather than a binary classification for normosmic and anosmic (9). In parallel, genetic overlap between $\mathrm{KS}$ and $\mathrm{nCHH}$ also exists, with several genes mutated in both subgroups (2).

Although long thought to be a monogenic disorder, frequent observations of incomplete penetrance and variable expressivity within and across families suggested this model was insufficient to fully explain the observed phenotypes in $\mathrm{CHH}$. Indeed, previous work by our team and others has shown that oligogenic inheritance (i.e. more than one gene mutated in the same individual) can at least partially explain some of these phenomena $(8,10)$. Synergistic effects between $\mathrm{CHH}$ genes have been also described in vitro (e.g. FGF8/FGFR1) (11) and in vivo (e.g. KISS1/KISS1R) (12). Oligogenicity has been proposed in heterogeneous genetic disorders such as Bardet-Biedl syndrome (BBS) (13) and retinitis pigmentosa (14). In addition, oligogenicity is also proposed for other endocrine diseases such as premature ovarian failure $(15,16)$ with the constellation of more than one gene mutated.

Pubertal timing is a highly heritable trait as up to $50-80 \%$ of the variance is explained by genetic factors (17). Consistently, CDGP runs in families with complex inheritance pattern (18), but in contrast to $\mathrm{CHH}$, little is known about the genetics of CDGP. A recent study identified mutations with low frequencies (MAF <2.5\%) in IGSF10 in 13\% of CDGP probands. IGSF10 is a large protein that is part of the immunoglobulin superfamily and appears to have a developmental role in GnRH neuron migration (19). In addition, genome-wide association studies (GWAS) evaluating common and rare variants in the timing of puberty identified significant associations with hundreds of loci, including regions near or within ANOS1, TACR3, LEPR and PCSK1 - four known $\mathrm{CHH}$ genes. Taken together, these loci account for $<3 \%$ of the variance in age of puberty onset $(20,21)$. In view of the possible overlap between the pathophysiology of delayed puberty and conditions of GnRH deficiency, few studies have searched for mutations in $\mathrm{CHH}$ genes in CDGP cohorts. A homozygous partial loss-of-function mutation in GNRHR was found in two brothers, one with CDGP and one with $\mathrm{CHH}$ (22). Of 50 CDGP patients investigated for mutations in TAC3 and TACR3, only one mutation in a single patient was found in the latter gene (23). However, a recent study screening $21 \mathrm{CHH}$ genes in a CDGP cohort $(n=56)$ found potentially pathogenic mutations in $14 \%$ of patients (3). Recently, low frequency (MAF <2.5\%) potentially pathogenic variants in IGSF10 were found in $10 \%$ of $\mathrm{CHH}$ patients (19), suggesting the hypothesis of a partial genetic overlap between CHH and CDGP.

Currently, the differential diagnosis between $\mathrm{CHH}$ and CDGP at early adolescence remains challenging, as both conditions present with isolated delay in puberty. Further, there are no specific biochemical markers to accurately differentiate these two disorders (24). In the current study, we explored the genetic architecture of 
both $\mathrm{CHH}$ and CDGP and to investigate whether genetic testing could assist in the differential diagnosis. We also characterized the genetic overlap between $\mathrm{KS}$ and $\mathrm{nCHH}$ using a comprehensive screening of all $\mathrm{CHH}$ genes and defined the mutational spectrum of $\mathrm{CHH}$ genes in the control population.

\section{Subjects and methods}

\section{Patient and control cohorts}

The study cohort includes $116 \mathrm{CHH}$ probands of European descent ( $n=61 \mathrm{KS}, n=55 \mathrm{nCHH}$ ) with a 2:1 male-tofemale ratio consistent with previous reports of male predominance (1). The diagnosis of $\mathrm{CHH}$ was determined by (1) absent or partial puberty by 17 years (25), (2) low/ normal serum gonadotropin levels in the setting of low serum testosterone/estradiol levels, (3) otherwise normal anterior pituitary function and (4) normal imaging of the hypothalamic-pituitary area (25). Olfaction was assessed by self-report and/or formal testing (9) using the UPSIT or Sniffin' Stick tests. When possible, family members were recruited for clinical and genetic studies.

The delayed puberty cohort consists of 72 unrelated probands with CDGP of primarily Finnish European origin and has been previously described in detail (26). All patients met the diagnostic criteria for CDGP, defined as (1) onset of Tanner genital stage II two SDs later than population average (i.e. in boys testicular volume $>3 \mathrm{~mL}$ after 13.5 years of age and in girls Tanner breast stage II after 13.0 years of age) (27). Medical history, clinical examination and routine laboratory tests were performed to exclude chronic illnesses, and the diagnosis of $\mathrm{CHH}$ was ruled out by spontaneous pubertal development at follow-up. All patients were followed until near-full pubertal development was attained (i.e., Tanner stage 4).

Ethnically matched controls (non-Finnish European (NFE) and Finnish European (FIN)) from the Exome Aggregation Consortium (ExAC) (28) were used for individual variant and gene mutation frequencies. Oligogenicity was assessed using the 'Cohorte Lausannoise' (CoLaus) control population, consisting of 405 participants of mixed European origin, phenotyped as described by Firmann and coworkers (29). This populationbased cohort was assembled as part of a cardiovascular risk study, and therefore, has a typical distribution of pubertal age relative to the general population. The ages of the cohort participants are 35-75 years old (mean $51 \pm 11$ years).

\section{DNA extraction and sequencing}

DNA was extracted from peripheral blood leukocytes using the PureGene kit (QIAGEN). Exome sequencing was performed on $\mathrm{CHH}$ and CDGP cohorts using the SureSelect V2 or V5 probes (Agilent) or the Nimblegen SeqCap EZ Exome V2 (Roche) and sequenced on the HiSeq 2000 platform (Illumina, San Diego, CA, USA) at either BGI (BGI, Shenzen, PRC) or Otogenetics (Otogenetics Corp., Atlanta, GA, USA). Exome sequencing on CoLaus DNA was performed at the Wellcome Trust Sanger Institute (WTSI) as part of a partnership between the Institute, the CoLaus principal investigators and the Quantitative Sciences department of GlaxoSmithKline (GSK, Brentford, UK).

\section{Definition of genes to be screened}

'CHH genes' are those which met the following criteria: (1) identified as $\mathrm{CHH}$ genes in Boehm and coworkers (2), (2) had publications demonstrating loss-of-function variants, (3) had been demonstrated to be expressed in organs/tissues relevant for GnRH biology and (4) covered by the exome capture probes. Twenty-four genes met these criteria: ANOS1, SEMA3A, FGF8, FGF17, SOX10, IL17RD, AXL, FGFR1, CHD7, HS6ST1, PCSK1, LEP, LEPR, FEZF1, NSMF, PROKR2, WDR11, PROK2, GNRH1, GNRHR, KISS1, KISS1R, TAC3 and TACR3. In addition, we screened the IGSF10 gene, recently implicated in CDGP and CHH (19).

\section{Bioinformatics analysis and downstream variants filtering}

Exome sequences from $\mathrm{CHH}$ probands, CDGP probands and CoLaus controls were analyzed following the Genome Analysis Toolkit (GATK) Best Practices (30). The computations were performed at the Vital-IT Center for High-Performance Computing of the Swiss Institute of Bioinformatics. Variants called with a genotype quality (GQ) $<50$ were excluded. The complete set of $\mathrm{CHH}$ gene variants from the ExAC database was downloaded from the ftp site (ftp://ftp.broadinstitute.org/pub/ExAC_ release/release0.3). Annotation was performed using SnpEff (31), version 4.0. Intronic variants within \pm 6 bp of exonic boundaries and predicted to affect splicing by MaxEnt (32) with a wild-type vs mutated site change of $\pm 20 \%$ were retained, as well as inframe/frameshift indels, stop gain, and missense variants. Protein-truncating variants (PTVs) were defined as frameshift, stop gain and splice variants (28). 
For the purpose of this study, we define as mutations (1) rare $(\mathrm{MAF}<1 \%)$ PTVs, (2) rare missense variants predicted to be damaging to protein function by at least one in silico algorithm (SIFT (33) or PolyPhen-2 (34)) and (3) loss-of-function variants based on in vitro studies, regardless of in silico predictions.

\section{Statistical analyses}

Statistics for individual and oligogenic variants in cases vs controls were performed using a two-tailed Fisher's exact test. Gene-based allele frequencies in ExAC were calculated dividing the sum of alternate allele counts in ethnically matched samples with the average of alleles inspected. Gene-collapsed rare variant association (RVA) tests in cases vs controls were calculated using mutated allele frequencies in a two-tailed Fisher's exact test. Statistical significance in gene-based RVA tests was defined using Bonferroni correction, dividing nominal significance (0.05) with the number of tests performed (i.e. genes analyzed, $n=25$ ); hence, the cutoff to determine significance was set at $P=0.002$.

\section{Ethics approval and consent to participate}

This study was approved by the ethics committee of the University of Lausanne. All participants provided written informed consent prior to study participation. The study protocol was approved by the Ethics Committee for Paediatrics, Adolescent Medicine and Psychiatry,
Hospital District of Helsinki and Uusimaa (and extended to encompass Kuopio, Tampere and Turku University Hospitals) (570/E7/2003). UK ethical approval was granted by the London-Chelsea NRES committee (13/ LO/0257). The study was conducted in accordance with the guidelines of The Declaration of Helsinki.

\section{Results}

\section{$\mathrm{CHH}$ genes are mutated in $51 \%$ of $\mathrm{CHH}$ probands but only in $7 \%$ in CDGP probands}

Exome sequencing was performed on $116 \mathrm{CHH}$ probands, and 59 (51\%) harbored mutations in 20 of the 25 genes evaluated (Fig. 1A and Supplementary Table 1, see section on supplementary data given at the end of this article). No mutations were identified in NSMF, FEZF1, PCSK1, LEP and LEPR. Nearly two-thirds of familial $\mathrm{CHH}$ probands carried mutations in $\mathrm{CHH}$ genes $(27 / 44,61 \%)$, while the frequency in sporadic probands was lower $(32 / 72,44 \%)$ (Supplementary Fig. 2).

FGFR1 and CHD7 were the most frequently mutated genes in $\mathrm{CHH}$ probands (Fig. 1A), and both were statistically enriched for mutations compared to ExAC NFE controls (Table 1 and Supplementary Fig. 1). All of the identified FGFR1 and CHD7 mutations were present in a heterozygous state (Supplementary Table 2). In addition, a significant enrichment of mutations was observed for SOX10, with a prevalence of $4 \%$ in $\mathrm{CHH}$ patients (Table 1 and Supplementary Table 1).
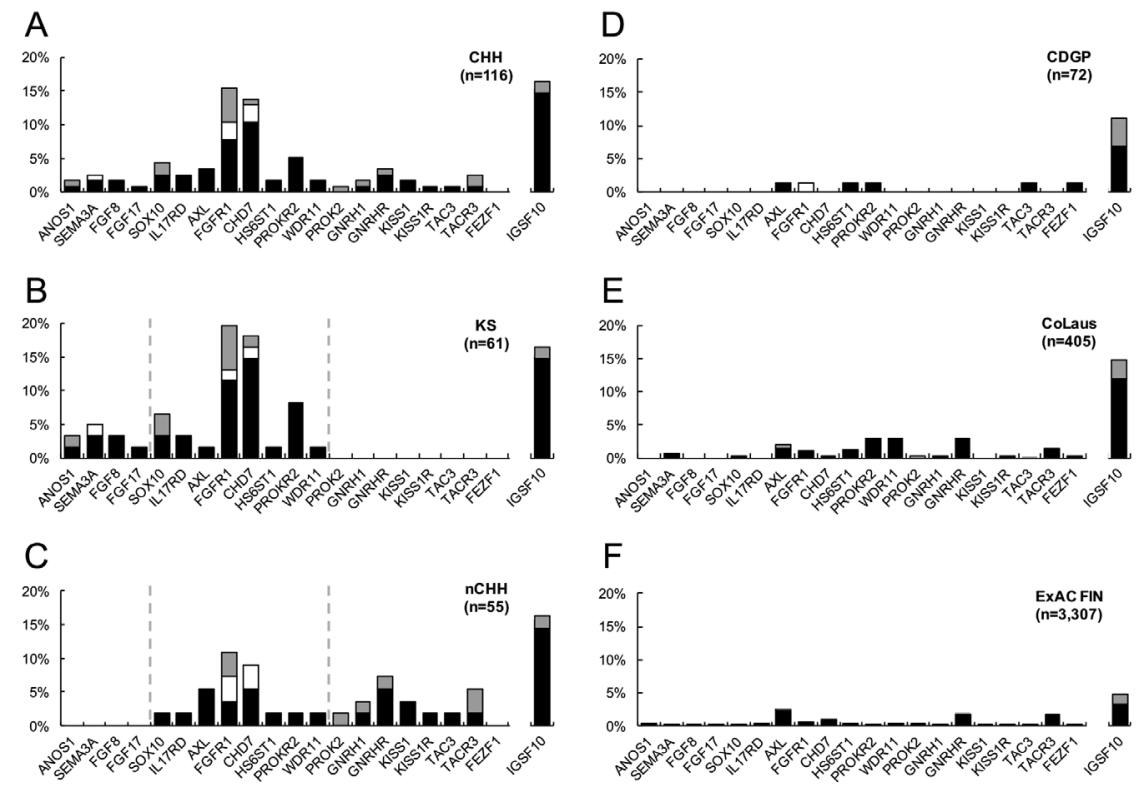

nonsynonymous $\square$ splicing $\square$ nonsense

\section{Figure 1}

$\mathrm{KS}$ and $\mathrm{nCHH}$ display both shared and specific genetic patterns, and CDGP is not characterized by genetic overlap with $\mathrm{CHH}$. Histograms showing $\mathrm{CHH}$ genes and IGSF10 mutational prevalence in (A) $\mathrm{CHH}$, (B) $\mathrm{KS},(C) \mathrm{nCHH}$, (D) CDGP, (E) CoLaus, and (F) ExAC Finnish (FIN) cohorts. The prevalence of probands with variants in each gene are noted in black for nonsynonymous (i.e. missense and inframe InDels), white for splicing, and gray for nonsense (i.e. frameshift and stop gained) variants. 

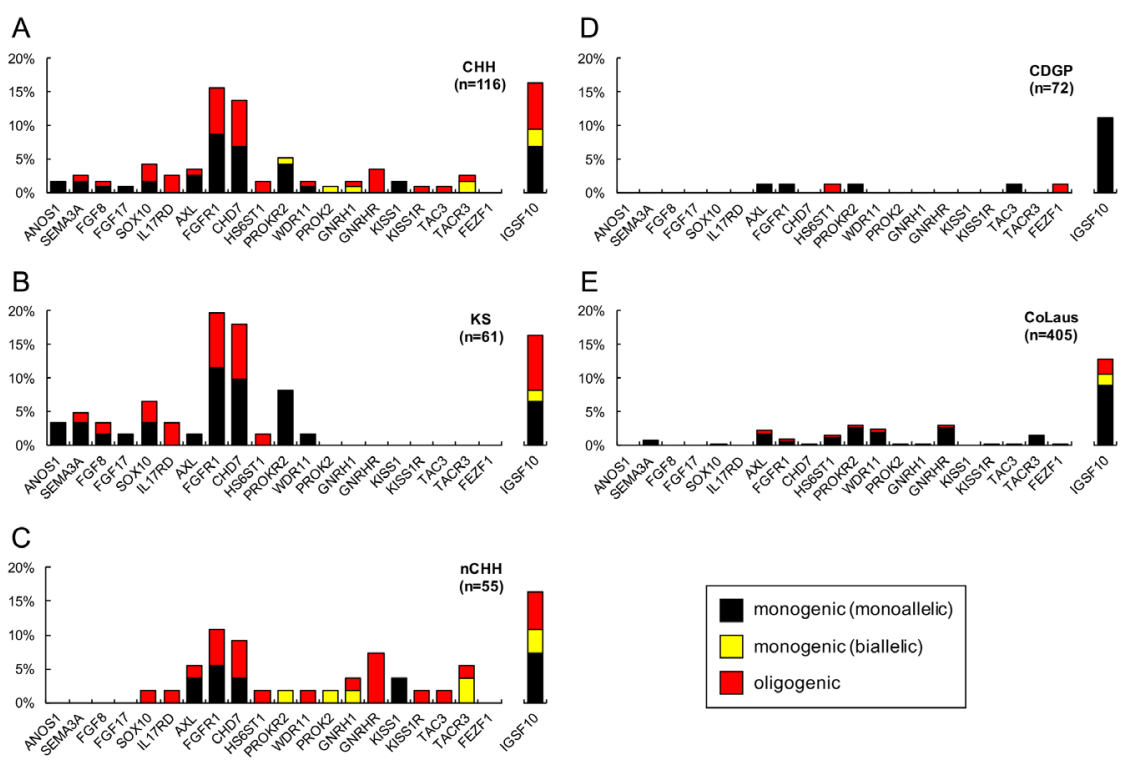

\section{Figure 2}

The majority of $\mathrm{CHH}$ genes are inherited in a oligogenic fashion in $\mathrm{CHH}$ probands, a trend not observed in CDGP probands and CoLaus controls. Histograms showing $\mathrm{CHH}$ genes mutational prevalence in $(\mathrm{A})$ $\mathrm{CHH},(\mathrm{B}) \mathrm{KS},(\mathrm{C}) \mathrm{nCHH},(\mathrm{D}) \mathrm{CDGP}$ and (E) CoLaus screened individuals. Each bar contains the frequency of each gene inheritance: monoallelic (gray), biallelic (yellow) or oligogenic (red).
Exome sequencing identified $7 \% \quad(n=5)$ of CDGP probands harboring mutations in the known $\mathrm{CHH}$ genes, all of which are heterozygous (Fig. 1D and Supplementary Table 3). Thus, the genetic profile of the CDGP cohort more closely resembles the controls (both ExAC Finnish and non-Finnish controls) rather than $\mathrm{CHH}$ probands. Among the six identified mutations, there were five missense and one intronic change predicted to affect splicing. Three mutations were private compared to 3307 Finnish ExAC controls. Only one CDGP proband harbored two mutated genes (oligogenicity) $(1.4 \%, P=0.002$ vs $\mathrm{CHH})$, a similar rate as observed in controls ( and Supplementary Table 2). Clinically, this CDGP patient had spontaneous puberty at 14.3 years and achieved normal adult testicular volume and testosterone levels over the subsequent 2.4 years, thereby excluding a diagnosis of $\mathrm{CHH}$.

\section{Prevalence of putative IGSF10 mutations in $\mathrm{CHH}$ is similar to CDGP}

We found a large number of $\mathrm{CHH}$ patients $(19 / 116,16.4 \%)$ harboring putative IGSF10 mutations compared to CDGP $(8 / 72,11.1 \%)$ (Fig. 1A, B, C and D). Our data did not show enrichment for mutations in our cohorts as similar frequencies were seen in controls (Fig. 1A, B, C and D).

\section{$\mathrm{KS}$ and $\mathrm{nCHH}$ show both exclusive and shared genetic architectures}

We examined the mutational spectrum relative to the two subgroups of $\mathrm{CHH}-\mathrm{KS}(n=61)$ and $\mathrm{nCHH}(n=55)$. Among KS, FGFR1 and CHD7 were the most frequently mutated genes, and together with $S O X 10$ are significantly enriched when compared to controls (Fig. 1B and Table 1). This finding is even more robust when evaluating the KS subgroup alone. Similarly, FGF8 showed a prevalence of $1.6 \%$ in $\mathrm{KS}$; yet, this association was not evident in the $\mathrm{CHH}$ cohort as a whole. Mutations in ANOS1, SEMA3A, FGF17 and FGF8 were only found in KS.

Among normosmic probands (nCHH), FGFR1 and CHD7 were also the most frequently mutated genes. Mutations in GNRHR and TACR3 were only found in nCHH (7\% and 5\%, respectively) (Fig. 1C). Further, FGFR1, KISS1, GNRHR and TACR3 were significantly enriched in nCHH cases compared to ExAC NFE controls (Table 1).

In addition to FGFR1 and CHD7, six other $\mathrm{CHH}$ genes (SOX10, IL17RD, AXL, HS6ST1, PROKR2 and WDR11) were mutated in both $\mathrm{KS}$ and $\mathrm{nCHH}$ (Fig. $1 \mathrm{~B}$ and $\mathrm{C}$ ). This represents an increased genetic overlap in comparison to prior report (2). Overall, these results indicate both exclusive and shared genetic architectures for both $\mathrm{KS}$ and $\mathrm{nCHH}$.

\section{nCHH probands are enriched with biallelic mutations}

Biallelic mutations (i.e. homozygous or compound heterozygous changes in the same gene) were found exclusively in $\mathrm{nCHH}(6 / 55,11 \%)$ and were not seen in KS $(P=0.01), \operatorname{CDGP}(P=0.006)$ or in CoLaus $\left(P=2.3 \times 10^{-6}\right)$ (Fig. 2). Furthermore, 4/15 (27\%) genes mutated in $\mathrm{nCHH}$ (GNRHR, GNRH1, PROKR2, PROK2, TACR3) only exhibited biallelic mutations, consistent with their recessive mode of inheritance (Fig. 2C and Supplementary Table 1). 


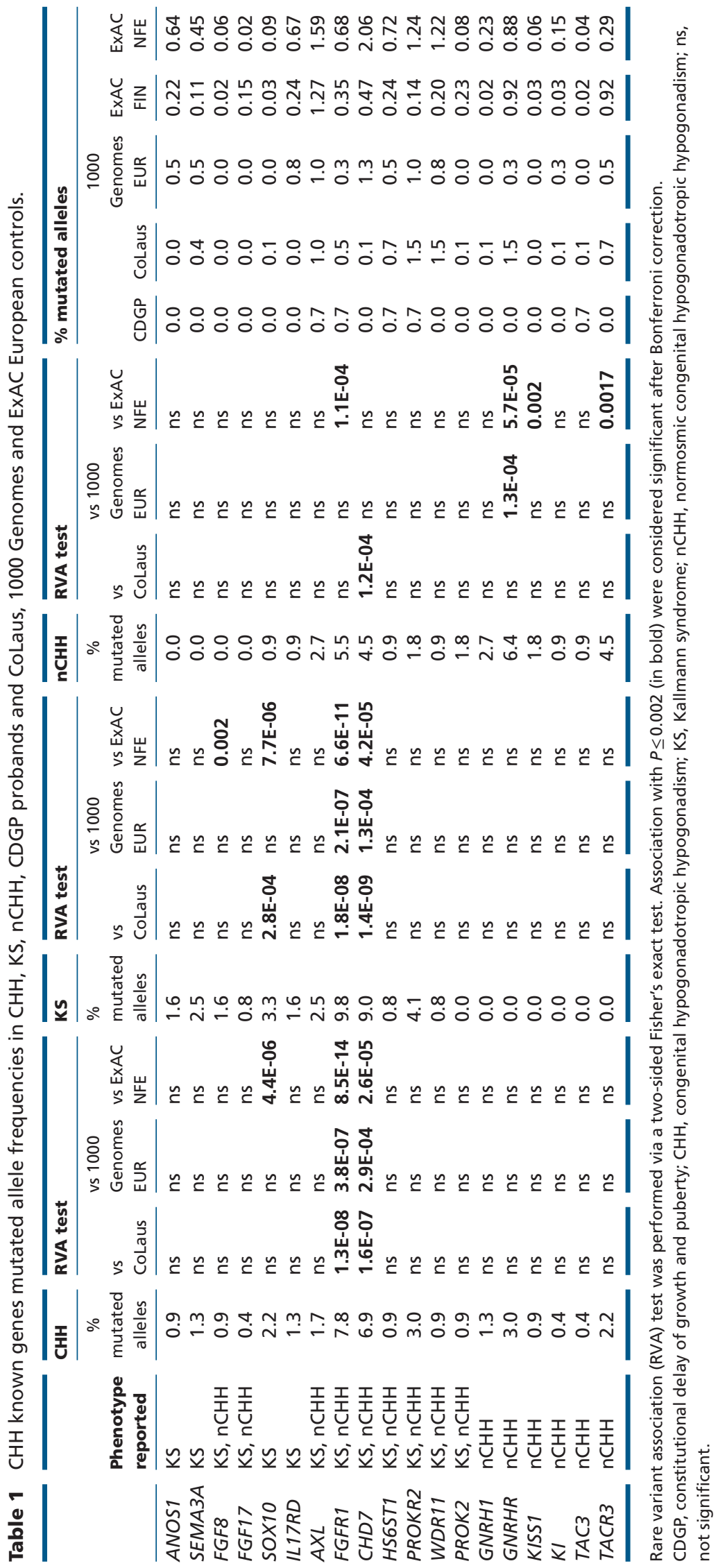




\section{Oligogenicity is a common factor in $\mathrm{CHH}$ patients}

Oligogenicity was present in 17/116 (15\%) of $\mathrm{CHH}$ probands (Fig. 3) - a higher frequency than previous reports of $2.5-7 \%(8,10)$. A significantly lower rate of oligogenicity was observed in controls (CoLaus: 2\%, $P=6.4 \times 10^{-7}$ ).

Additionally, although monogenic inheritance was more frequent in KS (46\%) compared to nCHH (25\%, $P=0.03)$, CDGP $\left(6 \%, P=3.7 \times 10^{-8}\right)$ and CoLaus $(16 \%$, $\left.P=4.6 \times 10^{-7}\right)$, similar frequencies of oligogenicity were identified in both KS (13\%) and nCHH (16\%) (Fig. 3 and Supplementary Table 3$)$.

Among the 20 mutated genes identified in $\mathrm{CHH}$ patients, $84 \%$ ( $n=16$ genes) participated in oligogenicity (Fig. 2A). Of these 16 genes, mutations in IL17RD, HS6ST1, KISS1R and TAC3 occurred exclusively in an oligogenic manner. ANOS1, FGF17, KISS1 and PROK2 were the only genes exclusively showing monogenic inheritance (Fig. 2A).

Among possible gene combinations, FGFR1 and $C H D 7$ was the most frequent pair interaction $(n=4)$, followed by FGFR1/IL17RD and CHD7/HS6ST1 ( $n=2)$ (Fig. 4A). One

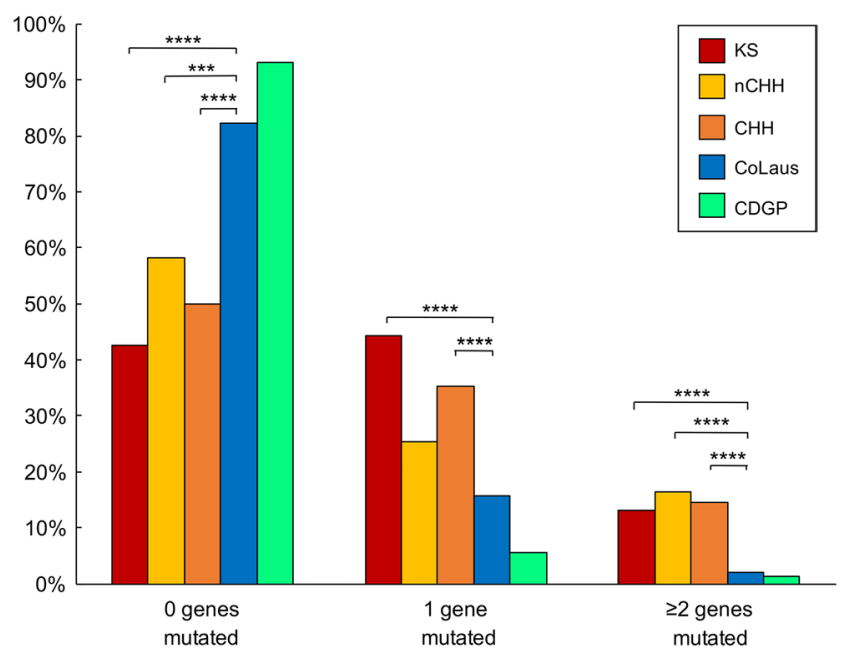

Figure 3

Oligogenicity is a common factor in $\mathrm{CHH}$, and it is not found in CDGP. Histogram showing the frequency of $\mathrm{KS}$ (red), $\mathrm{nCHH}$ (yellow), $\mathrm{CHH}$ (orange), CoLaus (blue) and CDGP (green) individuals having no rare variants in $\mathrm{CHH}$ genes, one gene mutated or at least two genes mutated (oligogenicity). Differences between $\mathrm{KS}, \mathrm{nCHH}$ and $\mathrm{CHH}$ vs CoLaus controls were analyzed via a two-sided Fisher's exact test. $P<0.05$ was considered significant. ${ }^{*} P<0.05$; ${ }^{* *} P<0.01 ; * * * P<0.001$; $* * * * P<0.0001$. Not significant differences among $\mathrm{KS}, \mathrm{nCHH}$ and $\mathrm{CHH}$ vs CoLaus are not displayed.
KS proband (Fig. 4B, Pedigree 1) carrying mutations in both $C H D 7$ and FGFR1, had two daughters after receiving fertility treatment. One of them carried both mutations and was eventually diagnosed with KS, while the second unaffected daughter did not harbor either of the two changes. In Pedigree 2, we identified three mutated genes (FGFR1, CHD7 and SOX10) in a KS proband. His KS brother showed overlapping FGFR 1 and SOX10 mutations. As there were no phenotypic differences between the proband and his sibling, the $\mathrm{CHD} 7$ mutation is likely not critical in the etiology of KS for this pedigree. Last, we identified a KS proband (Fig. 4B, Pedigree 3) harboring an IL17RD mutation inherited from his anosmic mother and a de novo FGFR1 mutation. We did not identify any $\mathrm{CHH}$ gene mutations in the anosmic father or the unaffected brother.

\section{The majority of mutations in $\mathrm{CHH}$ probands are private}

When assessing the mutations identified in $\mathrm{CHH}$ probands, more than half of them $(38 / 68,56 \%)$ were not found in the ExAC NFE controls $(n=33$ 370), and therefore, are private.

In total, we identified 1492 putative mutations in EXAC NFE controls and 80 mutations in $72 / 405$ (18\%) CoLaus controls. However, the majority of mutations in CoLaus $\left(89 \%, P=6.6 \times 10^{-4}\right)$ (Fig. 2E) occurred in a monoallelic pattern. Given the variant-based (rather than sample-based) nature of the ExAC database, the allelic patterns in these controls could not be assessed.

\section{Protein-truncating variants are enriched in CHH probands}

PTVs are defined as changes predicted to severely disrupt genes, i.e. splicing, frameshift and stop gain variants. A large fraction of the discovered mutations in $\mathrm{CHH}$ probands were PTVs $(20 / 68,29 \%)$, while the frequency was significantly lower (5\%) in ExAC NFE controls $\left(P=1.0 \times 10^{-9}\right)$. Overall, $18 \%(n=21)$ of patients in our cohort harbored at least one PTV in the known $\mathrm{CHH}$ genes. Specifically, the $\mathrm{CHH}$ cohort was enriched for splice variants in FGFR1 $\left(2.6 \%, P=1.7 \times 10^{-4}\right)$ and for frameshift/ stop gain variants in FGFR1 $\left(8 \%, P=6.9 \times 10^{-13}\right)$, SOX10 $\left(1.7 \%, P=1.2 \times 10^{-5}\right)$ and TACR3 $\left(1.7 \%, P=4.9 \times 10^{-3}\right)$ when compared to ExAC NFE.

We observed that $80 \%$ of PTVs in $\mathrm{CHH}$ were in genes with a high constraint to this type of variants (i.e. probability of being loss-of-function intolerant $-\mathrm{pLi}>0.9$ ) 
A

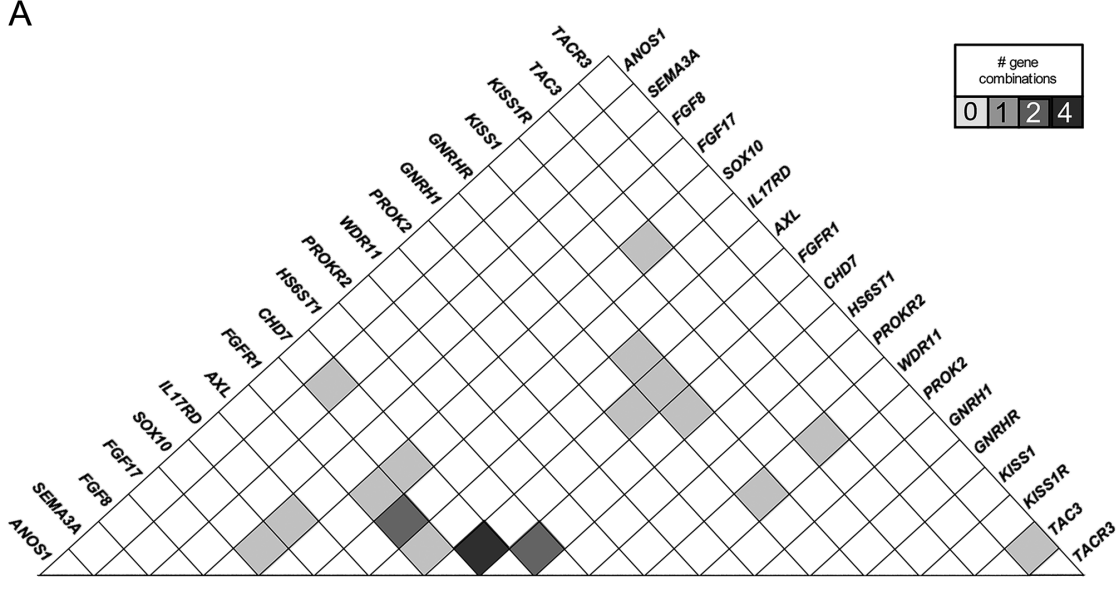

B

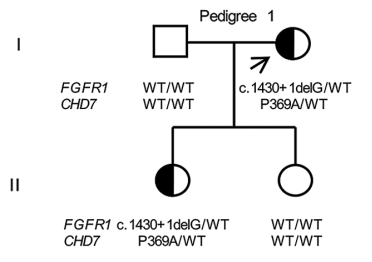

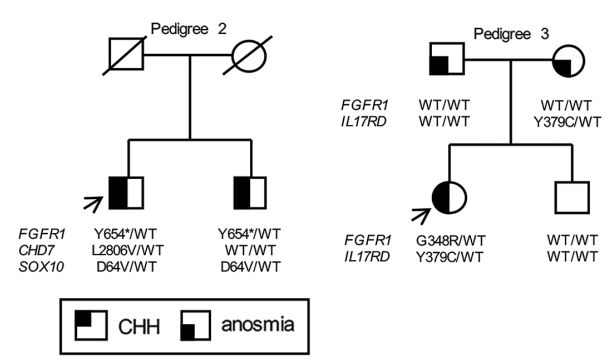

\section{Figure 4}

FGFR1 and CHD7 are frequently inherited in digenic fashion among $\mathrm{CHH}$ probands. (A) Matrix showing shading-coded frequencies $\mathrm{CHH}$ genes digenic combinations. (B) Available pedigrees of $\mathrm{CHH}$ probands displaying oligogenic inheritance. Circles denote females; squares denote males; arrows depict probands; WT denotes wild-type.
(28), a higher frequency than in ExAC controls $(P=0.002)$. Conversely, the majority of PTVs in ExAC (60\%) were present in PTV-tolerant genes ( $\mathrm{pLi}<0.1$ ) (Fig.3 and Supplementary Fig. 4). Furthermore, a large majority of PTVs found in CHH probands $(16 / 20,80 \%)$ are heterozygous and occur in $\mathrm{CHH}$ genes where mutations are inherited in an autosomal dominant mode. Moreover, all of the PTVs identified in $\mathrm{CHH}$ probands likely result in haploinsufficiency, as they do not lie within the last exon (or in last 50bp of penultimate exon) and are therefore likely to be subjected to nonsense-mediated decay (NMD) (35).

\section{Discussion}

CDGP and $\mathrm{CHH}$ are part of a continuum of GnRH deficiency, ranging from transiently delayed to a complete absence of puberty. However, it is challenging to make a clinical distinction between $\mathrm{CHH}$ and CDGP in adolescents presenting with delayed puberty. In this study, we investigated the genetic overlap between these two conditions focusing on rare variants in known $\mathrm{CHH}$ genes and IGSF10, a gene recently identified in CDGP. CHH and CDGP differ in terms of the number of patients harboring mutations in individual $\mathrm{CHH}$ genes (51\% vs $7 \%)$, as well as the overall mutational load in
CHH genes (oligogenicity). In both instances, the CDGP probands more closely resembled the control cohort. We also observed similar frequencies of putative IGSF10 mutations in CDGP and $\mathrm{CHH}$ probands, although higher than previously reported (19). It is important to note, however, that the previous study by Howard and coworkers utilized a different filtering strategy to identify low-frequency variants, specifically focusing on variants with MAF of $<2.5 \%$ - a level consistent with the frequency of CDGP. Notably, the present study focused on variants with MAF $<1.0 \%$ given the rarity of the $\mathrm{CHH}$ phenotype. Thus, it is not surprising that different results would be achieved. This would suggest that variants with MAF $1.0-2.5 \%$ may contribute more strongly to the CDGP phenotype. Indeed, the most frequent IGSF10 variant in the CDGP cohort (p.Glu161Lys) has a MAF of $2.0 \%$ in the Finnish population. In the current study, the variants identified have not been functionally validated nor has segregation with trait within pedigree been analyzed, both of which were used to identify definitive pathogenic variants in the previous study by Howard and coworkers. Furthermore, the lack of an association of IGSF10 mutations with CDGP or $\mathrm{CHH}$ in the current study may reflect a limitation of rare variant burden testing. It is possible that in a very large gene such as IGSF10, there may be a large number of non-causal variants or both 
protective and deleterious variants, and the proportion of these may vary between different populations. In summary, the current data show that the genetic profile of the Finnish CDGP patients, while enriched for rare putative pathogenic variants in IGSF10 as compared to ethnically matched controls, closely resemble the profile of both ExAC Finnish and non-Finnish control cohorts with respect to known $\mathrm{CHH}$ genes.

Recent GWAS studies have identified hundreds of loci associated with puberty onset in the general population $(20,21)$, with several signals lying close to or within $\mathrm{CHH}$ genes suggestive of a genetic overlap between $\mathrm{CHH}$ and CDGP. However, GWAS signals may result from intergenic, intronic, promoter or other regulatory changes that are not detected by exome sequencing. Therefore, our results in $\mathrm{CHH}$ and CDGP patients could have missed pathogenic mutations in regulatory regions. Notably, a genome-wide significant signal in the coding sequence was reported in TACR3 (p.Trp275*), a mutation identified in $\mathrm{nCHH}$ in this report as well as in previous studies $(8,36,37)$. Although prior GWAS studies have not identified an association for its ligand TAC3, we identify mutations in TAC3 in both $\mathrm{CHH}$ and CDGP cohorts. Further, TAC3 mutations were previously reported in $\mathrm{CHH}$ as well as CDGP (3). Combined, these data implicate the neurokinin B pathway in both CHH and CDGP. We propose that larger studies examining pathways rather than individual genes identified by GWAS are required to further elucidate the genetic overlap between $\mathrm{CHH}$ and CDGP.

Using whole exome sequencing to examine a larger number of CHH genes in our study, we identified mutations in $51 \%$ of $\mathrm{CHH}$ cases. This is increased in relation to prior reports of 31\% (10) and 35\% (8) respectively. Our data are mostly consistent with a recent publication by Francou et al. (38) that evaluated a large cohort of $\mathrm{nCHH}$ patients of European descent for pathogenic variants in KISS1R, GNRHR, TACR3, KISS1, TAC3 and GNRH1.

We report a genetic overlap between KS and nCHH. Using a gene-collapsed rare variant association study (RVAS) on the entire $\mathrm{CHH}$ cohort, we found significant associations for FGFR1, CHD7 and SOX10. Separating $\mathrm{CHH}$ into $\mathrm{KS}$ and $\mathrm{nCHH}$, the burden test remained significant for FGFR1 in both subgroups while CHD7 and SOX10 were significant only for KS. Notably, significant association appears for FGF8 in KS while GNRHR, TACR3 and KISS1 showed association only in $\mathrm{nCHH}$. A significant enrichment of rare variants in the RNF216 gene was recently shown in patients with $\mathrm{CHH}$ and cerebellar ataxia (39). In contrast, no enrichment in KISS1 rare variants was detected in $1025 \mathrm{CHH}$ patients, without respect to the phenotypic subgroups (12). These data point toward the importance of phenotypic clustering to identify novel associated genes $(8,40)$. Finally, our results show that such burden tests might miss associations in important genes like KISS1R, because of the low frequency of rare variants in both patient and control population.

Oligogenicity occurs in our study in $15 \%$ of $\mathrm{CHH}$ cases as compared to $2.5 \%$ and $7 \%$ in previous reports $(8,10)$ using nearly identical strategies for variant classification. This increase is due in part to the increased number of $\mathrm{CHH}$ genes screened using exome sequencing. Although this study does not provide molecular evidences of oligogenic interactions, previous studies demonstrated that oligogenicity is a critical factor in $\mathrm{CHH}$ pathogenesis $(8,11,41)$. Recent guidelines from the American College of Medical Genetics aid in the identification of pathogenic variants in a clinical setting (42). While these guidelines are suited only for monogenic disorders, they do provide a structured framework from which to evaluate variants. Using these guidelines, all ACMG pathogenic or likely pathogenic variants were also classified as pathogenic in the current study (Supplementary Table 2). However, a large number of pathogenic variants detected in the current study were classified as unknown significance using ACMG guidelines. This is primarily due to the weight assigned to (i) familial segregation that is not applicable in the setting of oligogenicity and (ii) detection of de novo mutations that was not possible in this study as parental DNA was not available for most probands.

The combination of mutations in both FGFR 1 and CHD7 occurred most frequently ( $n=4$ probands). These two genes might play coordinated roles during GnRH neuron development and migration as $\mathrm{CHD} 7$ regulates the transcription of Fgf8, a major ligand for FGFR1 in GnRH neuron ontogeny (11). Moreover, both FGFR1 and $\mathrm{CHD7}$ are expressed in relevant tissues for $\mathrm{CHH}$, such as the olfactory bulb and hypothalamus (43). A previous report also suggested functional interactions between these genes, as $\mathrm{CHH}$ patients with mutations in FGFR1 and CHD7 exhibit overlaps in associated phenotypes (cleft lip/palate, coloboma or ear anomalies) (44).

One notable exception to oligogenicity was ANOS1 which was inherited in an exclusively monoallelic fashion due to its $\mathrm{X}$-linked recessive mode of inheritance and high penetrance. Mutations in other genes such as TAC3, KISS1, PROK2 and PROKR2 were primarily biallelic and oligogenic interactions were not observed - likely due to their recessive mode of inheritance. Interestingly, the frequency of monogenic inheritance in KS was significantly 
higher than in nCHH. To date, it is unclear whether this difference is due to distinct genetic architecture or that 'missing' partners in an oligogenic inheritance for KS have yet to be discovered.

We discovered putatively pathogenic mutations in $\mathrm{CHH}$ genes in up to $17 \%$ of controls, which at first glance seems counterintuitive. Importantly, oligogenicity was only rarely found in controls (2\%), further supporting the oligogenic model of $\mathrm{CHH}$ pathogenesis. Additionally, many of the putative heterozygous mutations in controls were found in genes with an autosomal recessive inheritance, which would explain the lack of obvious reproductive phenotypes among controls. Further, $\mathrm{CHH}$ and controls differ markedly for PTVs (29\% vs 5\%, respectively), and the PTVs in controls were less likely to be pathogenic.

This study expands our understanding of the genetic architecture of both $\mathrm{CHH}$ and CDGP and highlights the very large proportion of cases of CDGP that are not explained by mutations in known genes. Further, the genetic profiles of $\mathrm{CHH}$ and CDGP appear to be distinct with respect to the $25 \mathrm{CHH}$ genes studied here, with the understanding that ethnic differences between groups (European vs Finnish) could contribute to this finding. This observation may facilitate differential diagnosis of $\mathrm{CHH}$ and CDGP in early adolescence when a clear and early diagnosis is critical to initiate timely induction of puberty in patients with $\mathrm{CHH}$. A genetic test resulting in (1) more than one $\mathrm{CHH}$ gene mutated (oligogenicity), (2) hemizygous ANOS1 mutations in male patients or (3) biallelic mutations in genes associated with autosomal recessive inheritance would favor a diagnosis of $\mathrm{CHH}$. Additional comprehensive studies in larger cohorts may enable genetic testing to inform a more precise differential diagnosis in the clinical setting.

\section{Supplementary data}

This is linked to the online version of the paper at https://doi.org/10.1530/ EJE-17-0568.

\section{Declaration of interest}

The authors declare that there is no conflict of interest that could be perceived as prejudicing the impartiality of this study.

\section{Funding}

This work was supported by the Swiss National Science Foundation grant (SNF 31003A 153328, N P) and by the Shenzhen Municipal Government of China (No. JSGG2015330171719763 and CXB201108250094A). S R H is funded by the Wellcome Trust (102745), Rosetrees Trust (M222) and the Barts and the London Charity (417/1551). L D is partly supported by the Academy of Finland (14135). W S D is supported by an NIHR Research Professorship.
Author contribution statement

N P and L D designed the research project. D C, J S A, N P, S R H, C X, G P, F S, A S and L D analyzed the data. J M, C C, J L, X L, H Y, J Z prepared and sequenced DNA. J S A and D C managed the project. S R H, CX, S S, L F, L M, P M B, C D G, A D P, W S D, J M F, M H, M L M, J L, C F, A N, F P H, D P, V P, $S P, R$ Q, G S, D A, D K, Sab S, O T I and O D E X team provided for samples DNA and phenotyping. D $C, J S A, C X$, and $N$ P wrote and prepared the original draft. A A D, G P S, B J S, J S A, N P, C X, L D, S R H reviewed and edited the manuscript.

\section{Acknowledgments}

The authors are grateful to the patients and families who contributed their time, medical information and DNA samples to this study. They thank all of the COST investigators for sharing DNA and patient information. They are grateful for access to the exome sequence data from the CoLaus cohort, which was sequenced as part of a partnership between the Wellcome Trust Sanger Institute, the CoLaus principal investigators and the Quantitative Sciences department of GlaxoSmithKline. They thank Prof. Jacques S Beckmann for his valuable suggestions during the preparation of the manuscript.

\section{References}

1 Mitchell AL, Dwyer A, Pitteloud N \& Quinton R. Genetic basis and variable phenotypic expression of Kallmann syndrome: towards a unifying theory. Trends in Endocrinology and Metabolism 201122 249-258. (https://doi.org/10.1016/j.tem.2011.03.002)

2 Boehm U, Bouloux PM, Dattani MT, de Roux N, Dode C, Dunkel L, Dwyer AA, Giacobini P, Hardelin JP, Juul A et al. Expert consensus document: European Consensus Statement on congenital hypogonadotropic hypogonadism - pathogenesis, diagnosis and treatment. Nature Reviews Endocrinology 201511 547-564. (https:// doi.org/10.1038/nrendo.2015.112)

3 Zhu J, Choa RE, Guo MH, Plummer L, Buck C, Palmert MR, Hirschhorn JN, Seminara SB \& Chan YM. A shared genetic basis for self-limited delayed puberty and idiopathic hypogonadotropic hypogonadism. Journal of Clinical Endocrinology and Metabolism 2015 100 E646-E654. (https://doi.org/10.1210/jc.2015-1080)

4 Raivio T, Falardeau J, Dwyer A, Quinton R, Hayes FJ, Hughes VA, Cole LW, Pearce SH, Lee H, Boepple P et al. Reversal of idiopathic hypogonadotropic hypogonadism. New England Journal of Medicine 2007357 863-873. (https://doi.org/10.1056/NEJMoa066494)

5 Waldstreicher J, Seminara SB, Jameson JL, Geyer A, Nachtigall LB, Boepple PA, Holmes LB \& Crowley WF Jr. The genetic and clinical heterogeneity of gonadotropin-releasing hormone deficiency in the human. Journal of Clinical Endocrinology and Metabolism $1996 \mathbf{8 1}$ 4388-4395. (https://doi.org/10.1210/jcem.81.12.8954047)

6 Legouis R, Hardelin JP, Levilliers J, Claverie JM, Compain S, Wunderle V, Millasseau P, Le Paslier D, Cohen D, Caterina D et al. The candidate gene for the X-linked Kallmann syndrome encodes a protein related to adhesion molecules. Cell $199167423-435$. (https://doi.org/10.1016/0092-8674(91)90193-3)

7 Franco B, Guioli S, Pragliola A, Incerti B, Bardoni B, Tonlorenzi R, Carrozzo R, Maestrini E, Pieretti M, Taillon-Miller P et al. A gene deleted in Kallmann's syndrome shares homology with neural cell adhesion and axonal path-finding molecules. Nature 1991353 529-536. (https://doi.org/10.1038/353529a0)

8 Miraoui H, Dwyer AA, Sykiotis GP, Plummer L, Chung W, Feng B, Beenken A, Clarke J, Pers TH, Dworzynski P et al. Mutations in FGF17, IL17RD, DUSP6, SPRY4, and FLRT3 are identified in individuals with congenital hypogonadotropic hypogonadism. American Journal of Human Genetics 201392 725-743. (https://doi. org/10.1016/j.ajhg.2013.04.008) 
9 Lewkowitz-Shpuntoff HM, Hughes VA, Plummer L, Au MG, Doty RL, Seminara SB, Chan YM, Pitteloud N, Crowley WF Jr \& Balasubramanian R. Olfactory phenotypic spectrum in idiopathic hypogonadotropic hypogonadism: pathophysiological and genetic implications. Journal of Clinical Endocrinology and Metabolism 201297 E136-E144. (https://doi.org/10.1210/jc.2011-2041)

10 Sykiotis GP, Plummer L, Hughes VA, Au M, Durrani S, NayakYoung S, Dwyer AA, Quinton R, Hall JE, Gusella JF et al. Oligogenic basis of isolated gonadotropin-releasing hormone deficiency. PNAS 2010107 15140-15144. (https://doi.org/10.1073/pnas.1009622107)

11 Falardeau J, Chung WC, Beenken A, Raivio T, Plummer L, Sidis Y, Jacobson-Dickman EE, Eliseenkova AV, Ma J, Dwyer A et al. Decreased FGF8 signaling causes deficiency of gonadotropinreleasing hormone in humans and mice. Journal of Clinical Investigation 2008118 2822-2831. (https://doi.org/10.1172/ JCI34538)

12 Chan YM, Broder-Fingert S, Paraschos S, Lapatto R, Au M, Hughes V, Bianco SD, Min L, Plummer L, Cerrato F et al. GnRH-deficient phenotypes in humans and mice with heterozygous variants in KISS1/Kiss1. Journal of Clinical Endocrinology and Metabolism 201196 E1771-E1781. (https://doi.org/10.1210/jc.2011-0518)

13 Beales PL, Badano JL, Ross AJ, Ansley SJ, Hoskins BE, Kirsten B, Mein CA, Froguel P, Scambler PJ, Lewis RA et al. Genetic interaction of BBS1 mutations with alleles at other BBS loci can result in non-Mendelian Bardet-Biedl syndrome. American Journal of Human Genetics 200372 1187-1199. (https://doi.org/10.1086/375178)

14 Kajiwara K, Berson EL \& Dryja TP. Digenic retinitis pigmentosa due to mutations at the unlinked peripherin/RDS and ROM1 loci. Science 1994264 1604-1608. (https://doi.org/10.1126/science.8202715)

15 Bouilly J, Beau I, Barraud S, Bernard V, Azibi K, Fagart J, Fevre A, Todeschini AL, Veitia RA, Beldjord C et al. Identification of multiple gene mutations accounts for a new genetic architecture of primary ovarian insufficiency. Journal of Clinical Endocrinology and Metabolism 2016101 4541-4550. (https://doi.org/10.1210/jc.2016-2152)

16 Patino LC, Beau I, Carlosama C, Buitrago JC, Gonzalez R, Suarez CF, Patarroyo MA, Delemer B, Young J, Binart N et al. New mutations in non-syndromic primary ovarian insufficiency patients identified via whole-exome sequencing. Human Reproduction 201732 1512-1520. (https://doi.org/10.1093/humrep/dex089)

17 Gajdos ZK, Hirschhorn JN \& Palmert MR. What controls the timing of puberty? An update on progress from genetic investigation. Current Opinion in Endocrinology, Diabetes and Obesity 200916 16-24. (https://doi.org/10.1097/MED.0b013e328320253c)

18 Wehkalampi K, Widen E, Laine T, Palotie A \& Dunkel L. Patterns of inheritance of constitutional delay of growth and puberty in families of adolescent girls and boys referred to specialist pediatric care. Journal of Clinical Endocrinology and Metabolism 200893 723-728. (https://doi.org/10.1210/jc.2007-1786)

19 Howard SR, Guasti L, Ruiz-Babot G, Mancini A, David A, Storr HL, Metherell LA, Sternberg MJ, Cabrera CP, Warren HR et al. IGSF10 mutations dysregulate gonadotropin-releasing hormone neuronal migration resulting in delayed puberty. ЕMBO Molecular Medicine 20168 626-642. (https://doi.org/10.15252/emmm.201606250)

20 Perry JR, Day F, Elks CE, Sulem P, Thompson DJ, Ferreira T, He C, Chasman DI, Esko T, Thorleifsson G et al. Parent-of-origin-specific allelic associations among 106 genomic loci for age at menarche. Nature 2014514 92-97. (https://doi.org/10.1038/nature13545)

21 Lunetta KL, Day FR, Sulem P, Ruth KS, Tung JY, Hinds DA, Esko T, Elks CE, Altmaier E, He C et al. Rare coding variants and X-linked loci associated with age at menarche. Nature Communication 201567756. (https://doi.org/10.1038/ncomms8756)

22 Lin L, Conway GS, Hill NR, Dattani MT, Hindmarsh PC \& Achermann JC. A homozygous R262Q mutation in the gonadotropin-releasing hormone receptor presenting as constitutional delay of growth and puberty with subsequent borderline oligospermia. Journal of Clinical Endocrinology and
Metabolism 200691 5117-5121. (https://doi.org/10.1210/jc.20060807)

23 Tusset C, Noel SD, Trarbach EB, Silveira LF, Jorge AA, Brito VN, Cukier P, Seminara SB, Mendonca BB, Kaiser UB et al. Mutational analysis of TAC3 and TACR3 genes in patients with idiopathic central pubertal disorders. Arquivos Brasileiros De Endocrinologia E Metabologia 201256 646-652. (https://doi.org/10.1590/S000427302012000900008)

24 Harrington J \& Palmert MR. Clinical review: distinguishing constitutional delay of growth and puberty from isolated hypogonadotropic hypogonadism: critical appraisal of available diagnostic tests. Journal of Clinical Endocrinology and Metabolism 2012 97 3056-3067. (https://doi.org/10.1210/jc.2012-1598)

25 Pitteloud N, Hayes FJ, Boepple PA, DeCruz S, Seminara SB, MacLaughlin DT \& Crowley WF Jr. The role of prior pubertal development, biochemical markers of testicular maturation, and genetics in elucidating the phenotypic heterogeneity of idiopathic hypogonadotropic hypogonadism. Journal of Clinical Endocrinology and Metabolism 200287 152-160. (https://doi.org/10.1210/ jcem.87.1.8131)

26 Wehkalampi K, Widen E, Laine T, Palotie A \& Dunkel L. Association of the timing of puberty with a chromosome 2 locus. Journal of Clinical Endocrinology and Metabolism 200893 4833-4839. (https:// doi.org/10.1210/jc.2008-0882)

27 Palmert MR \& Dunkel L. Clinical practice. Delayed puberty. New England Journal of Medicine 2012366 443-453. (https://doi. org/10.1056/NEJMcp1109290)

28 Lek M, Karczewski KJ, Minikel EV, Samocha KE, Banks E, Fennell T, O'Donnell-Luria AH, Ware JS, Hill AJ, Cummings BB, et al. Analysis of protein-coding genetic variation in 60706 humans. Nature 2016 536 285-291. (https://doi.org/10.1038/nature19057)

29 Firmann M, Mayor V, Vidal PM, Bochud M, Pecoud A, Hayoz D, Paccaud F, Preisig M, Song KS, Yuan X et al. The CoLaus study: a population-based study to investigate the epidemiology and genetic determinants of cardiovascular risk factors and metabolic syndrome. BMC Cardiovascular Disorders 20088 6. (https://doi. org/10.1186/1471-2261-8-6)

30 DePristo MA, Banks E, Poplin R, Garimella KV, Maguire JR, Hartl C, Philippakis AA, del Angel G, Rivas MA, Hanna M et al. A framework for variation discovery and genotyping using next-generation DNA sequencing data. Nature Genetics 201143 491-498. (https://doi. org/10.1038/ng.806)

31 Cingolani P, Platts A, Wang le L, Coon M, Nguyen T, Wang L, Land SJ, Lu X \& Ruden DM. A program for annotating and predicting the effects of single nucleotide polymorphisms, SnpEff: SNPs in the genome of Drosophila melanogaster strain w1118; iso-2; iso-3. Fly 20126 80-92. (https://doi.org/10.4161/fly.19695)

32 Yeo G \& Burge CB. Maximum entropy modeling of short sequence motifs with applications to RNA splicing signals. Journal of Computational Biology 200411 377-394. (https://doi. org/10.1089/1066527041410418)

$33 \mathrm{Ng}$ PC \& Henikoff S. SIFT: predicting amino acid changes that affect protein function. Nucleic Acids Research 200331 3812-3814. (https:// doi.org/10.1093/nar/gkg509)

34 Adzhubei IA, Schmidt S, Peshkin L, Ramensky VE, Gerasimova A, Bork P, Kondrashov AS \& Sunyaev SR. A method and server for predicting damaging missense mutations. Nature Methods 20107 248-249. (https://doi.org/10.1038/nmeth0410-248)

35 Nagy E \& Maquat LE. A rule for termination-codon position within intron-containing genes: when nonsense affects RNA abundance. Trends in Biochemical Sciences 199823 198-199. (https://doi. org/10.1016/S0968-0004(98)01208-0)

36 Gianetti E, Tusset C, Noel SD, Au MG, Dwyer AA, Hughes VA, Abreu AP, Carroll J, Trarbach E, Silveira LF et al. TAC3/TACR3 mutations reveal preferential activation of gonadotropin-releasing hormone release by neurokinin B in neonatal life followed by 
reversal in adulthood. Journal of Clinical Endocrinology and Metabolism 201095 2857-2867. (https://doi.org/10.1210/jc.2009-2320)

37 Xu N, Kim HG, Bhagavath B, Cho SG, Lee JH, Ha K, Meliciani I, Wenzel W, Podolsky RH, Chorich LP et al. Nasal embryonic LHRH factor (NELF) mutations in patients with normosmic hypogonadotropic hypogonadism and Kallmann syndrome. Fertility and Sterility 201195 1613.e1611-1620.e1617. (https://doi. org/10.1016/j.fertnstert.2011.01.010)

38 Francou B, Paul C, Amazit L, Cartes A, Bouvattier C, Albarel F, Maiter D, Chanson P, Trabado S, Brailly-Tabard S et al. Prevalence of KISS1 Receptor mutations in a series of 603 patients with normosmic congenital hypogonadotrophic hypogonadism and characterization of novel mutations: a single-centre study. Human Reproduction 2016 31 1363-1374. (https://doi.org/10.1093/humrep/dew073)

39 Margolin DH, Kousi M, Chan YM, Lim ET, Schmahmann JD, Hadjivassiliou M, Hall JE, Adam I, Dwyer A, Plummer L et al. Ataxia, dementia, and hypogonadotropism caused by disordered ubiquitination. New England Journal of Medicine 2013368 1992-2003. (10.1056/NEJMoa1215993)

40 Villanueva C, Jacobson-Dickman E, Xu C, Manouvrier S, Dwyer AA, Sykiotis GP, Beenken A, Liu Y, Tommiska J, Hu Y et al. Congenital hypogonadotropic hypogonadism with split hand/foot malformation: a clinical entity with a high frequency of FGFR1 mutations. Genetics in Medicine 201517 651-659. (https://doi. org/10.1038/gim.2014.166)

41 Dode C, Teixeira L, Levilliers J, Fouveaut C, Bouchard P, Kottler ML, Lespinasse J, Lienhardt-Roussie A, Mathieu M, Moerman A et al. Kallmann syndrome: mutations in the genes encoding prokineticin-2 and prokineticin receptor-2. PLoS Genetics 20062 e175. (https://doi. org/10.1371/journal.pgen.0020175)

42 Richards S, Aziz N, Bale S, Bick D, Das S, Gastier-Foster J, Grody WW, Hegde M, Lyon E, Spector E et al. Standards and guidelines for the interpretation of sequence variants: a joint consensus recommendation of the American College of Medical Genetics and Genomics and the Association for Molecular Pathology. Genetics in Medicine 201517 405-424. (https://doi. org/10.1038/gim.2015.30)

43 Sanlaville D, Etchevers HC, Gonzales M, Martinovic J, ClementZiza M, Delezoide AL, Aubry MC, Pelet A, Chemouny S, Cruaud C et al. Phenotypic spectrum of CHARGE syndrome in fetuses with CHD7 truncating mutations correlates with expression during human development. Journal of Medical Genetics 200643 211-217. (https:// doi.org/10.1136/jmg.2005.036160)

44 Hardelin JP \& Dode C. The complex genetics of Kallmann syndrome: KAL1, FGFR1, FGF8, PROKR2, PROK2, et al. Sexual Development 2008 2 181-193. (https://doi.org/10.1159/000152034)

Received 11 July 2017

Revised version received 31 December 2017

Accepted 1 February 2018 